\title{
Effect of Ginkgo biloba extract on matrix metalloproteinase-3 expression in a rat model of chondrocyte injury
}

\author{
J.Z. Zeng ${ }^{1,2}$, L.F. Ma1', H. Meng' ${ }^{1}$, H.M. Yu' ${ }^{1}$, Y.K. Zhang' ${ }^{2}$ and A. Guo' \\ 'Department of Orthopaedics, Beijing Friendship Hospital, Capital Medical University, \\ Beijing, China \\ ${ }^{2}$ Department of Orthopaedics, Beijing Luhe Hospital, Capital Medical University, \\ Beijing, China \\ Corresponding author: A. Guo \\ E-mail: cxywenli88@163.com
}

Genet. Mol. Res. 14 (4): 18280-18286 (2015)

Received August 28, 2015

Accepted October 24, 2015

Published December 23, 2015

DOI http://dx.doi.org/10.4238/2015.December.23.15

\begin{abstract}
A rat model with cartilage chondrocyte injury was established using interleukin-1 $\beta$ (IL-1 $\beta$ ) to investigate the effect of Ginkgo biloba extract (EGb) on matrix metalloproteinase-3 (MMP-3) expression. Rat chondrocytes were extracted and randomly divided into six groups: control group, IL-1 $\beta$ (model) group, IL-1 $\beta$ + dexamethasone group, and IL-1 $\beta$ + EGb group (both high and low dose groups). Reverse transcriptase polymerase chain reaction and enzyme-linked immunosorbent assay were used to detect MMP-3 expression. Compared to the MMP-3 mRNA level in the control group, MMP-3 mRNA level significantly increased in the model group $(P<0.05)$. The application of dexamethasone or EGb significantly decreased the MMP-3 mRNA level $(P<0.05)$. MMP-3 mRNA and protein levels decreased in the EGb-treated group, especially in the high-dose group, compared to those in the dexamethasone group $(P<0.05)$. EGb
\end{abstract}


may reduce MMP-3 production during IL-1 $\beta$-induced chondrocyte damage and protect chondrocytes to some extent, with better efficacy at high doses.

Key words: Ginkgo biloba extract; IL-1ß; Matrix metalloproteinase; Chondrocyte

\section{INTRODUCTION}

Osteoarthritis $(\mathrm{OA})$ is common in clinical settings occurring widely in middle-aged and elderly. Inflammatory factors can cause chondrocytes to produce cytokines and accelerate matrix degradation. Interleukin 1 (IL-1) is closely related to OA onset. Previous study on rabbits confirmed that IL-1 $\beta$ damages articular chondrocytes (Zhao, 2011).

Ginkgo biloba extract (EGb) is widely used currently. It reduces signs of aging, is an oxygen free-radical scavenger, and improves cell metabolism in cardiovascular disease. Furthermore, it can significantly improve clinical symptoms of OA.

This study aimed to investigate EGb's effect on matrix metalloproteinase-3 (MMP-3) expression in IL-1 $\beta$-induced chondrocyte damage by using primary rat chondrocytes and RT-PCR and ELISA detection.

\section{MATERIAL AND METHODS}

\section{Animals}

SPF-grade, two-week old, female SD rats were provided by Zhejiang University Laboratory Animal Center (certification No. SCXK Zhe 2007-2007).

Rats were used for all experiments and all procedures were approved by the Animal Ethics Committee of our hospital.

\section{Instruments}

Clean bench (Formal 205 type, USA). Microplate reader REF (Tecna, UK). Oscillator, enzymatic colorimetric analyzer and spectrophotometer (Shanghai Jinghong Biotechnology Co., Ltd.). Inverted microscope (Olympus, Japan). Incubator (Napco, USA).

\section{Reagents}

MMP-3 ELISA Kit, Dulbecco's modified essential medium (DMEM), fetal bovine serum, penicillin-streptomycin, trypsin, 10\% formalin, toluidine blue, MTT, dimethyl sulfoxide, dexamethasone, recombinant rat IL-1ß (Sigma, USA), EGb (Wilmore, Germany).

\section{Chondrocyte isolation and cultivation}

Two-week old female SD rats were anesthetized and euthanized. Cartilage was extracted after opening the knee joint. Primary chondrocytes were digested and cultured. Toluidine blue was applied to detect chondrocyte phenotype. Acidic glycosaminoglycan present in the extracellular matrix showed abnormal blue and purple staining (Figure 1). 


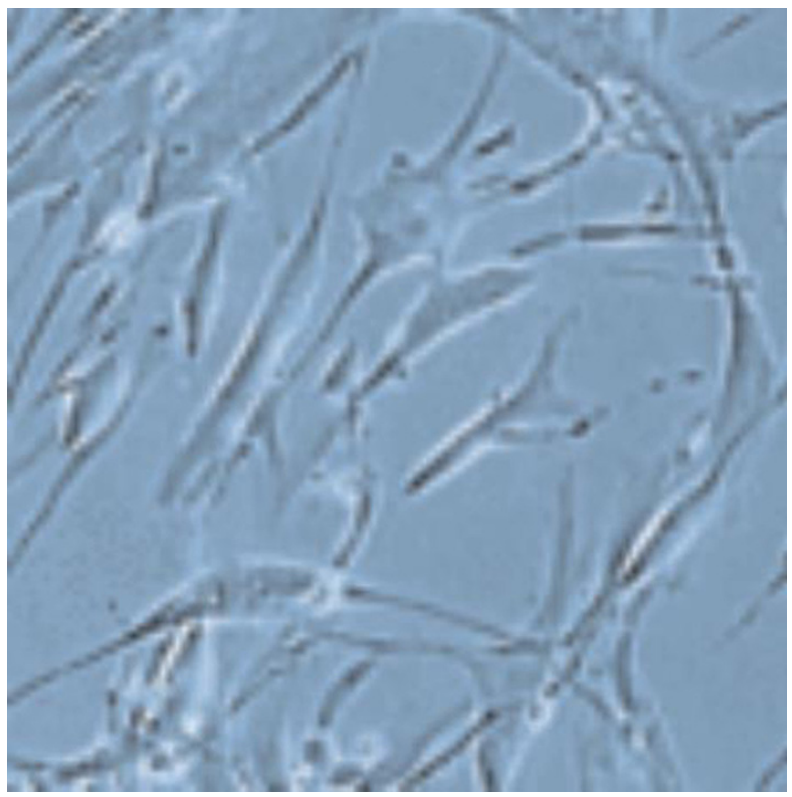

Figure 1. Metachromatic toluidine blue staining of primary chondrocytes (400X).

\section{Cell culture and grouping}

Chondrocytes were seeded in 96-well plates and incubated with $100 \mu \mathrm{L}$ medium. The cells were divided as follows: control group, normal chondrocytes; experimental group 1, chondrocytes treated with $5 \mu \mathrm{g} / \mathrm{L} \mathrm{IL-1 \beta}$; experimental group 2, chondrocytes treated with $5 \mu \mathrm{g} / \mathrm{L} \mathrm{IL-1 \beta}$ and $10^{-6}$ $\mathrm{mg} / \mathrm{L}$ dexamethasone; experimental group 3 , chondrocytes treated with $5 \mu \mathrm{g} / \mathrm{L} \mathrm{IL}-1 \beta$ and EGb. Group 3 was further divided into two subgroups, 3a, chondrocytes treated with $5 \mu \mathrm{g} / \mathrm{L} \mathrm{IL}-1 \beta$ and 40 $\mathrm{mg} / \mathrm{L} \mathrm{EGb}$; and 3b, chondrocytes treated with $5 \mu \mathrm{g} / \mathrm{L} \mathrm{IL-1 \beta}$ and $160 \mathrm{mg} / \mathrm{L} \mathrm{EGb}$.

\section{Reverse transcriptase polymerase chain reaction (RT-PCR)}

The cells were collected after being treated with drugs for $24 \mathrm{~h}$ and total RNA was isolated. PCR product $(5 \mu \mathrm{L})$ was analyzed by agarose electrophoresis after PCR reaction to calculate MMP-3 mRNA content.

\section{Enzyme-linked immunosorbent assay (ELISA)}

Twenty microliters of diluted standard product was added to the corresponding reaction holes to prepare the standard curve and then $20 \mu \mathrm{L}$ of samples was added to each hole. After washing the plate five times, $100 \mu \mathrm{L}$ of enzyme reagent was added. The plate was washed another five times after incubation at $37^{\circ} \mathrm{C}$ for $30 \mathrm{~min}$. Color agent $(100 \mu \mathrm{L})$ was added to each hole and the plate was incubated at $37^{\circ} \mathrm{C}$ for $15 \mathrm{~min}$. The reaction was terminated by adding $50 \mu \mathrm{L}$ termination liquid. The absorbance value (OD value) was measured at a wavelength of $450 \mathrm{~nm}$. The sample concentration was calculated according to the $\mathrm{OD}$ value and standard curve. 


\section{Statistical analysis}

All statistical analyses were performed using SPSS17.0 software (Chicago, IL, USA). Numerical data were presented as means and standard deviation. Differences between multiple groups were analyzed using LSD test. $\mathrm{P}<0.05$ was considered statistically significant.

\section{RESULTS}

\section{Chondrocyte morphology}

Chondrocytes in the IL-1 $\beta$ group grew slowly and its cells presented with shrinkage and declining activity, as shown by microscopy. Cell viability in the IL-1 $\beta+$ dexamethasone group was better than that in the IL-1 $\beta$ group with less shrinkage of cells. Cells in the IL-1 $\beta+$ high-dose EGb group were similar to those cells in the control group. Cells grew better with high-dose EGb (Figure 2).

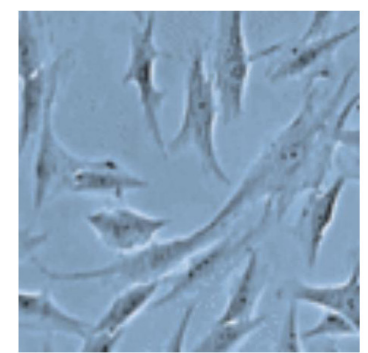

A

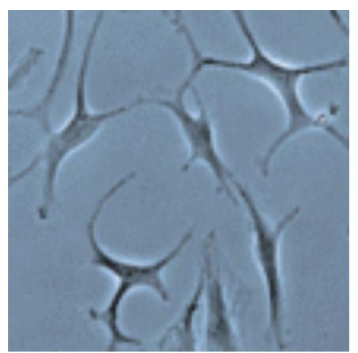

B

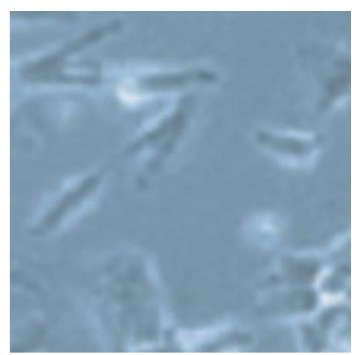

$\mathrm{C}$

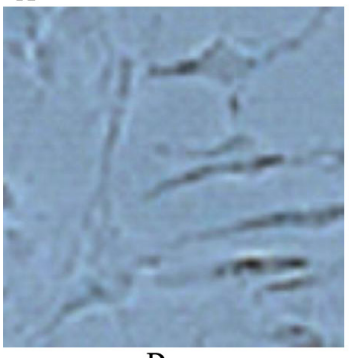

D

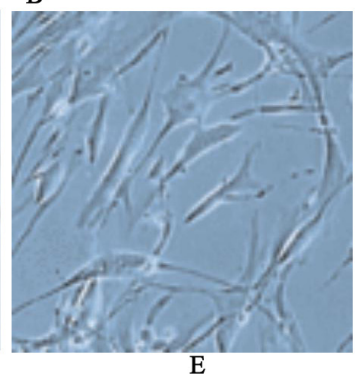

Figure 2. Chondrocyte morphology (400X). (A) Chondrocytes from model (IL-1 $\beta$-treated) cells; (B) cells after 10-6 $\mathrm{mg} / \mathrm{L}$ dexamethasone treatment; (C) low-dose (40 mg/L) EGb-treated cells; (D) cells treated with $160 \mathrm{mg} / \mathrm{L} \mathrm{EGb;} \mathrm{(E)}$ normal control (untreated) cells.

\section{MMP-3 mRNA expression}

The MMP-3 mRNA level increased significantly in the IL-1 $\beta$ group compared with that of the normal control $(P<0.05)$, suggesting that IL-1 $\beta$ can damage chondrocytes. Compared with the IL-1 $\beta$ + dexamethasone group and the IL-1 $\beta$ + EGb group, the IL-1 $\beta$ group showed increased MMP-3 mRNA level $(P<0.05)$, indicating that dexamethasone and EGb could treat IL-1 $\beta$-induced chondrocyte damage. MMP-3 mRNA level was markedly lower in the IL-1 $\beta+E G b$ group than that in the IL-1 $\beta$ + dexamethasone group, especially in the high-dose group $(P<0.05)$, suggesting $E G b$ had better treatment effect than dexamethasone with high-dose EGb having stronger effect (Table 1). 
Table 1. MMP-3 content detected by RT-PCR.

\begin{tabular}{ll}
\hline Group & MMP-3 mRNA \\
\hline Normal control & $0.2011 \pm 0.010$ \\
Model & $1.7284 \pm 0.011^{\star}$ \\
Dexamethasone-treated & $1.0012 \pm 0.015^{\sharp}$ \\
Low-dose EGb-treated & $0.0864 \pm 0.012^{\star}$ \\
High-dose EGb-treated & $0.2082 \pm 0.001^{@}$ \\
\hline
\end{tabular}

${ }^{*} \mathrm{P}<0.05$, compared with normal control; ${ }^{*} \mathrm{P}<0.05$, compared with model group; ${ }^{\mathrm{P}} \mathrm{P}<0.05$, compared with dexamethasone group; @P < 0.05, compared with low-dose EGb group. EGb: Gingko biloba extract; MMP-3: matrix metalloproteinase-3.

\section{MMP-3 content comparison by ELISA}

Compared with the MMP-3 level in normal control cells, the MMP-3 level increased significantly in the IL-1 $\beta$-damaged chondrocytes $(P<0.05)$. Compared with the IL-1 $\beta+$ dexamethasone group and the IL-1 $\beta+E G b$ group, the IL-1 $\beta$ group had increased MMP-3 level $(P<0.05)$. MMP-3 content was markedly lower in the IL-1 $\beta+E G b$ group than that in the IL-1 $\beta+$ dexamethasone group, especially in the high-dose group $(P<0.05)$ (Table 2$)$.

\begin{tabular}{|c|c|}
\hline Group & MMP-3 \\
\hline Normal control & $32.215 \pm 2.01$ \\
\hline Model & $56.875 \pm 3.85^{\star}$ \\
\hline Dexamethasone-treated & $43.125 \pm 2.15^{\#}$ \\
\hline Low-dose EGb-treated & $40.021 \pm 2.12^{8}$ \\
\hline High-dose EG- treated & $32.281 \pm 2.31 @$ \\
\hline
\end{tabular}

\section{DISCUSSION}

$\mathrm{OA}$ is a cartilage-matrix metabolism disorder characterized by joint degeneration involving cartilage and bone degradation (ZHANG et al., 2009). Numerous studies have found that cytokines are involved in OA occurrence and development (von Rossum et al., 2011; Hong, 2012).

IL-1 is an important inflammatory mediator in the body and can be distinguished as IL-1 $\alpha$ and IL-1 $\beta$. As an important extracellular component, IL-1 $\beta$ is highly expressed in the chondrocytes of OA (Jiao, 2000). It was pointed out that IL-1 is closely associated with OA pathogenesis. IL-1 can alter chondrocytes' structure, improve chondrocyte function, promote apoptosis, degrade the extracellular matrix, and is involved in bone and joint metabolism (Bajo et al., 2015; Karisnan et al., 2015). IL-1 not only inhibits proteoglycan synthesis in chondrocytes, but also can increase production and activity of multiple joint enzymes to promote collagen and matrix degradation (Semper et al., 2014).

In this study, we extracted primary chondrocytes from rats. After treatment with $5 \mu \mathrm{g} / \mathrm{L}$ IL$1 \beta$, the cells distributed loosely and grew gradually with shrinkage and decreased activity. RT-PCR and ELISA results showed that MMP-3 was overexpressed in the IL- $1 \beta$ group, suggesting that IL$1 \beta$ could damage rat chondrocytes.

MMPs belong to the $\mathrm{Zn}^{2+}$-, $\mathrm{Ca}^{2+}$-dependent proteolytic enzyme family that is involved in 
cartilage extracellular matrix synthesis and degradation (Takimoto et al., 2014). Numerous studies have found that MMP-1, 3, and 13 are closely related to OA occurrence and progression (Hossain et al., 2008; Aerts et al., 2014; Muto et al., 2014). Among them, MMP-3 could cleave multiple extracellular matrixes including gelatin and adhesion protein, and stimulate MMP-1 synergy. MMP-3 was overexpressed in chondrocytes treated with IL-1 $\beta$, which is consistent with the results of the previous literature.

Dexamethasone is commonly used to treat various inflammatory diseases and has moderate effect on $\mathrm{OA}$ and rheumatoid arthritis. However, long-term or high-dose dexamethasone should not be used since it may cause cell apoptosis and hormone-related side effects (Chung et al., 2011; Jia et al., 2011; Sekine et al., 2014; Shantha Kumara et al., 2014). Studies revealed that single high-dose dexamethasone could cause chondrocyte toxicity resulting in loss of cell viability and irreversible damage (Naves et al., 2011; Braun et al., 2012; Dragoo et al., 2012).

$\mathrm{EGb}$ is widely used clinically in the management of pain, asthma, and diarrhea. It can eliminate oxygen free radicals, promote cell metabolism, and ameliorate OA patients' symptoms, although the drug mechanism still needs further study (Dubey et al., 2004).

Taken together, $5 \mu \mathrm{g} / \mathrm{L} \mathrm{IL-1 \beta}$ could damage chondrocytes. Further investigation showed that the MMP-3 level increased significantly in the IL-1 $1 \beta$ group compared with that of the normal control $(P<0.05)$. Compared with the IL-1 + dexamethasone group and the IL-1 $\beta+E G b$ group, the IL-1 $\beta$ group showed obviously increased MMP-3 levels $(P<0.05)$, indicating that dexamethasone and EGb could reduce IL-1 $\beta$-induced chondrocyte damage. The MMP-3 level was markedly lower in the IL-1 $\beta+E G b$ group than that in the IL-1 $\beta$ + dexamethasone group, especially in the high-dose group $(P<0.05)$, suggesting $E G b$ had better treatment effect than dexamethasone and the high-dose EGb showed stronger effect.

In summary, IL-1 $\beta$ can cause chondrocyte damage. EGb could reduce MMP-3 production in this chondrocyte damage, thereby protecting chondrocytes. High doses of EGb exhibited better effect.

\section{Conflicts of interest}

The authors declare no conflict of interest.

\section{ACKNOWLEDGMENTS}

We thank the anonymous reviewers for reviewing this manuscript.

\section{REFERENCES}

Aerts J, Nys J, Moons L, Hu TT, et al. (2014). Altered neuronal architecture and plasticity in the visual cortex of adult MMP-3deficient mice. Brain Struct. Funct. 220: 2675-89.

Bajo M, Varodayan FP, Madamba SG, Robert AJ, et al. (2015). IL-1 interacts with ethanol effects on GABAergic transmission in the mouse central amygdala. Front. Pharmacol. 6: 49.

Braun HJ, Wilcox-Fogel N, Kim HJ, Pouliot MA, et al. (2012). The effect of local anesthetic and corticosteroid combinations on chondrocyte viability. Knee Surg. Sports Traumatol. Arthrosc. 20: 1689-1695.

Chung YJ, Lee JI, Chong S, Seok JW, et al. (2011). Anti-proliferative effect and action mechanism of dexamethasone in human medullary thyroid cancer cell line. Endocr. Res. 36: 149-157.

Dragoo JL, Danial CM, Braun HJ, Pouliot MA, et al. (2012). The chondrotoxicity of single-dose corticosteroids. Knee Surg. Sports Traumatol. Arthrosc. 20: 1809-1814.

Dubey AK, Shankar PR, Upadhyaya D and Deshpande VY (2004). Ginkgo biloba-an appraisal. Kathmandu Univ. Med. J. (KUMJ) 2: 225-229. 
Hong KD (2012). Clinical study day moxibustion yang Hanning Knee Osteoarthritis in Traditional Chinese Medicine 27: $2227-2230$.

Hossain MA, Park J, Choi SH and Kim G (2008). Dexamethasone induces apoptosis in proliferative canine tendon cells and chondrocytes. Vet. Comp. Orthop. Traumatol. 21: 337-342.

Jia J, Yao W, Guan M, Dai W, et al. (2011). Glucocorticoid dose determines osteocyte cell fate. FASEB J. 25: $3366-3376$.

Jiao YT (2000). Interleukin-1 and dexamethasone on human condylar cartilage cell proliferation, metabolism and procollagen genes Chin. J. Trauma 16: 94.

Karisnan K, Bakker AJ, Song Y, Noble PB, et al. (2015). Interleukin-1 Receptor Antagonist Protects against Lipopolysaccharide Induced Diaphragm Weakness in Preterm Lambs. PLoS One 10: e0124390.

Muto T, Kokubu T, Mifune Y, Inui A, et al. (2014). Temporary inductions of matrix metalloprotease-3 (MMP-3) expression and cell apoptosis are associated with tendon degeneration or rupture after corticosteroid injection. J. Orthop. Res. 32: 1297-1304.

Naves MA, Pereira RM, Comodo AN, de Alvarenga ELFC, et al. (2011). Effect of dexamethasone on human osteoblasts in culture: involvement of beta1 integrin and integrin-linked kinase. Cell Biol. Int. 35: 1147-1151.

Sekine C, Nanki T and Yagita H (2014). Macrophage-derived delta-like protein 1 enhances interleukin-6 and matrix metalloproteinase 3 production by fibroblast-like synoviocytes in mice with collagen-induced arthritis. Arthritis Rheumatol. 66: 2751-2761.

Semper RP, Mejias-Luque R, Gross C, Anderl F, et al. (2014). Helicobacter pylori-induced IL-1beta secretion in innate immune cells is regulated by the NLRP3 inflammasome and requires the cag pathogenicity island. J. Immunol. 193: 3566-3576.

Shantha Kumara HM, Gaita DJ, Miyagaki H, Yan X, et al. (2014). Minimally invasive colorectal resection is associated with significantly elevated levels of plasma matrix metalloproteinase 3 (MMP-3) during the first month after surgery which may promote the growth of residual metastases. Surg. Endosc. 28: 3322-3328.

Takimoto K, Kawashima N, Suzuki N, Koizumi Y, et al. (2014). Down-regulation of inflammatory mediator synthesis and infiltration of inflammatory cells by MMP-3 in experimentally induced rat pulpitis. J. Endod. 40: 1404-1409.

von Rossum A, Krall R, Escalante NK and Choy JC (2011). Inflammatory cytokines determine the susceptibility of human CD8 T cells to Fas-mediated activation-induced cell death through modulation of FasL and c-FLIP(S) expression. J. Biol. Chem. 286: 21137-21144.

Zhao DJ (2011). Effects of Ginkgo biloba extract on interleukin $-1 \beta$ damage articular chondrocytes MMP-3 and TIMP-1. Chin. Integrat. Med. Surg. 2: 72-74.

Zhang M, Wang Y, Li Y-Y and Zhao YQ (2009). Effect of Bitongling Granule medicated serum on rabbit articular chondrocytes cultured in vitro. Chin. J. Trad. Chin. Med. Pharm. 1: 026. 